Instructions for authors, subscriptions and further details:

http://brac.hipatiapress.com

\title{
La Videoperformance como Crítica Feminista a la Familia Patriarcal. Análisis de Semiotics of the Kitchen (Martha Rosler, 1975)
}

Miguel Alfonso Bouhaben ${ }^{1}$

1) Escuela Superior Politécnica del Litoral, ESPOL, Escuela de Diseño y Comunicación Visual, EDCOM. Guayaquil (Ecuador)

Date of publication: February $3^{\text {rd }}, 2016$

Edition period: February 2016 - June 2016

To cite this article: Bouhaben, M. A. (2015). La videoperformance como crítica feminista a la familia patriarcal. Análisis de Semiotics of the kitchen (Martha Rosler, 1975). Barcelona, Research, Art, Creation, 4(1), 8-31. doi: 10.17583/brac.2016.1427

To link this article: http://dx.doi.org/10.17583/brac.2016.1427

\section{PLEASE SCROLL DOWN FOR ARTICLE}

The terms and conditions of use, except where otherwise noted, are related to the Open Journal System and to Creative Commons Attribution License (CCBY). The indication must be expressly stated when necessary. 


\section{Videoperformance as Critical Feminist Family Patriarchal. Analysis of Semiotics of the Kitchen (Martha Rosler, 1975)}

Miguel Alfonso Bouhaben Escuela Superior Politécnica del Litoral, ESPOL, School of Design and Visual Communication, EDCOM. Guayaquil (Ecuador)

(Received: 16 February 2015; Accepted: 11 December 2015; Published: 3 February 2016)

\section{Abstract}

Feminist criticism has always been in the spotlight for the family as a result of political construction idelógico male-dominant power. This article aims to determine both the forms of social control of women in the domestic sphere, as diversion practices and meanings to those seeking to offset constraints. To do this, we analyze the videoperformance Semiotics of the kitchen of Martha Rosler as a case in which rupture modes of the dominant order are exemplified in three fields: language, identity and politics. In the analytical exercise of this audiovisual text establish a dialogue with the theories of Jacques Derrida, Jacques Lacan, Michel Foucault and Gilles Deleuze and feminist theories, the thesis mainly around the issue of gender, Judith Butler poses assuming that the legacy of these philosophers structuralist and poststructuralist.

Keywords: Feminism, family, Martha Rosler, video performance

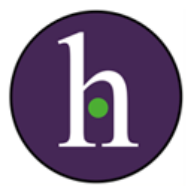


BRAC - Barcelona Research Art Creation. Vol. 4 No. 1, February 2016, pp. 8-31

\section{La Videoperformance como Crítica Feminista a la Familia Patriarcal. Análisis de Semiotics of the Kitchen (Martha Rosler, 1975)}

Miguel Alfonso Bouhaben Escuela Superior Politécnica del Litoral, ESPOL, Escuela de Diseño y Comunicación Visual, EDCOM. Guayaquil (Ecuador)

(Recibido: 16 Febrero 2015; Aceptado: 11 Diciembre 2015; Publicado: 3 Febrero 2016)

\section{Resumen}

La crítica feminista ha tenido siempre en el punto de mira a la familia como resultado de la construcción ideológico-política del poder dominante masculino. El presente artículo tiene por objeto determinar tanto las formas de control social de las mujeres en el espacio doméstico y familiar diseñado por el orden patriarcal occidental, como las prácticas de desvío y descentramiento que pretenden resignificar, desde las prácticas de la videoperformance, dichas coacciones. Para ello, analizaremos la videoperformance Semiotics of the kitchen (Martha Rosler, 1975) como caso en el que se ejemplifican los modos de ruptura del orden familiar dominante en tres campos: el lenguaje, la identidad y la política. En el ejercicio analítico de este texto audiovisual estableceremos un diálogo con las teorías de Jaques Derrida, Jacques Lacan, Michel Foucault y Gilles Deleuze y con las teorías feministas, fundamentalmente con las tesis en torno al problema del género, que Judith Butler plantea asumiendo, y a su vez criticando, el legado de estos filósofos estructuralistas y postestructuralistas.

Palabras clave: Feminismo, familia, Martha Rosler, videoperformance

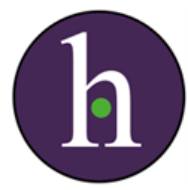


lo largo de la historia del arte la representación de la mujer ha sido configurada desde las coordenadas de la mirada masculina. En un mundo donde la mujer deviene una minoría marginal, una propiedad sin voz ni voto, un ser carente de autonomía política; en un universo dominado por la tiranía de lo masculino, la representación de la mujer es relegada en exclusiva al ámbito doméstico o reducida a puro objeto de deseo sexual. Su cuerpo es un cuerpo dócil y disciplinado. Un cuerpo sometido a automatismos impuestos y regulados por el poder masculino. Las luchas feministas del siglo XIX iniciaron un proceso de liberación femenina que alcanza su mayor expresividad reivindicativa en las prácticas críticas de los años 60 y 70 del siglo XX. Y es justamente en este periodo de emergencia del feminismo más radical y crítico cuando la performance alcanza su edad dorada. Ahora bien, ¿en qué medida esta forma de arte feminista pone en crisis la figura mítica del artista, que no deja de ser, como afirma Carol Armstrong (2006), una figura netamente patriarcal? ¿De qué modo las nuevas prácticas feministas de la performance amplían el canon del arte? ¿Cuál es la posición que adoptan respecto a los modos de regulación social encarnados en la estructura familiar?

Si bien es cierto que las artes de la presencia y de la acción corporal han sido ejercidas por artistas masculinos como Vito Acconci y Bruce Nauman -quizá dos de los referentes más insignes de esta práctica artística- no deja de ser relevante que estas disciplinas artísticas hayan sido practicadas mayoritariamente por mujeres (Baigorri, 2004). Ellas son las que en el campo de arte "más a menudo han utilizado este procedimiento de exploración del cuerpo." (Belloir, 1981, p. 23). Sin duda esto se debe a que tradicionalmente la representación de la mujer ha sido relegada una forma alienada dentro de la cultura dominante ya que el poder de la enunciación artística ha estado en manos masculinas. Videoperformers como Marina Abramovich, Yoko Ono, Linda Benglis, Joan Jonas, Gina Pane, Martha Rosler o Valie Export van a mostrar a través de la parodia, de la fragmentación del orden social, de la crítica al lenguaje y de la inversión de roles, otra realidad de la mujer a través del uso del vídeo.

Justificar y clasificar la amplia producción artística de estas videoperformers o realizar un eje comparativo entre sus prácticas y los conceptos forjados por la teoría feminista sería una labor ingente que excedería en mucho nuestras pretensiones. Ahora bien, sí que es nuestra intención trazar, en la medida de lo 
posible, un mapa de los conceptos que se establecen en la crítica a la reclusión de la mujer al espacio doméstico (crítica que la teoría feminista ha ido definiendo en su posición desviada respecto al orden social del patriarcado, entendido como un modo de opresión y de desigualdad) entresacados del análisis textual de la ya clásica performance de Martha Rosler Semiotics of the kitchen (1975). En definitiva, se trata de encontrar las ideas clave de la crítica a la familia de la teoría feminista a través de la interpretación de esta performance grabada en vídeo. Aunque más que una interpretación lo que pretendemos es buscar conexiones, entrecruzamientos y desvíos más allá del poder centralizador y significante de la lectura hermenéutica. Se trata, por tanto, de deletrear el texto y de estudiar su estructuración -al modo de Roland Barthes (2001) en su obra $S / Z$ - en su interacción con la crítica feminista.

\section{Pedagogía Rosleriana}

La citada video-performance de Martha Rosler supone una acción pedagógica que muestra los efectos de la dominación masculina a través de una crítica del espacio doméstico como lugar del trabajo de la madre de familia. La política dominante del patriarcado, impuesta por los roles preestablecidos para el hombre y la mujer, fomenta una imagen de lo que deberían ser los comportamientos masculinos y femeninos según las prescripciones de la sociedad occidental. Teóricas feministas como Monica Witting (2006) entienden que el orden patriarcal ha impuesto las diferencias sexuales como una suerte de anterioridad ontológica que permite que los cuerpos adquieran un significado. Es más, esa división prediscursiva es la que permite organizar los roles sociales y, en consecuencia, entender el trabajo familiar como algo natural y no como un constructo social: "Esta división prediscursiva y anterior a toda formación social posee asimismo consecuencias sociológicas: desde ella se va a dividir y organizar el trabajo y los roles sociales de los individuos. Hay, por tanto, una división natural del trabajo en la familia." (Witting, 2006, p. 25). Por su parte, Judith Butler parte también de la crítica de la nominalización que somete y domestica los cuerpos: "El nombrar el sexo es un acto de dominación, un performativo institucionalizado que crea y legisla la realidad social al requerir la construcción discursiva/perceptual de los cuerpos de acuerdo con los principios de diferencia sexual." (2007, p. 146) De este modo, la dominación masculina, que se ejerce mediante el lenguaje, delimita las funciones sociales de la mujer y la recluye en el espacio 
doméstico. Por tanto, la familia patriarcal reduce la operatividad de la mujer al ámbito privado del hogar: lugar de la explotación del hombre sobre la mujer.

Semiotics of the kitchen es una acción registrada en vídeo en la que la artista busca mostrar la crítica. de la representación de la mujer en los medios de comunicación, sus roles sociales y su función laboral en el seno familiar. El vídeo de Martha Rosler es un único plano secuencia, en perspectiva frontal, que se abre con la artista sosteniendo una pizarra donde aparece el título de la obra.

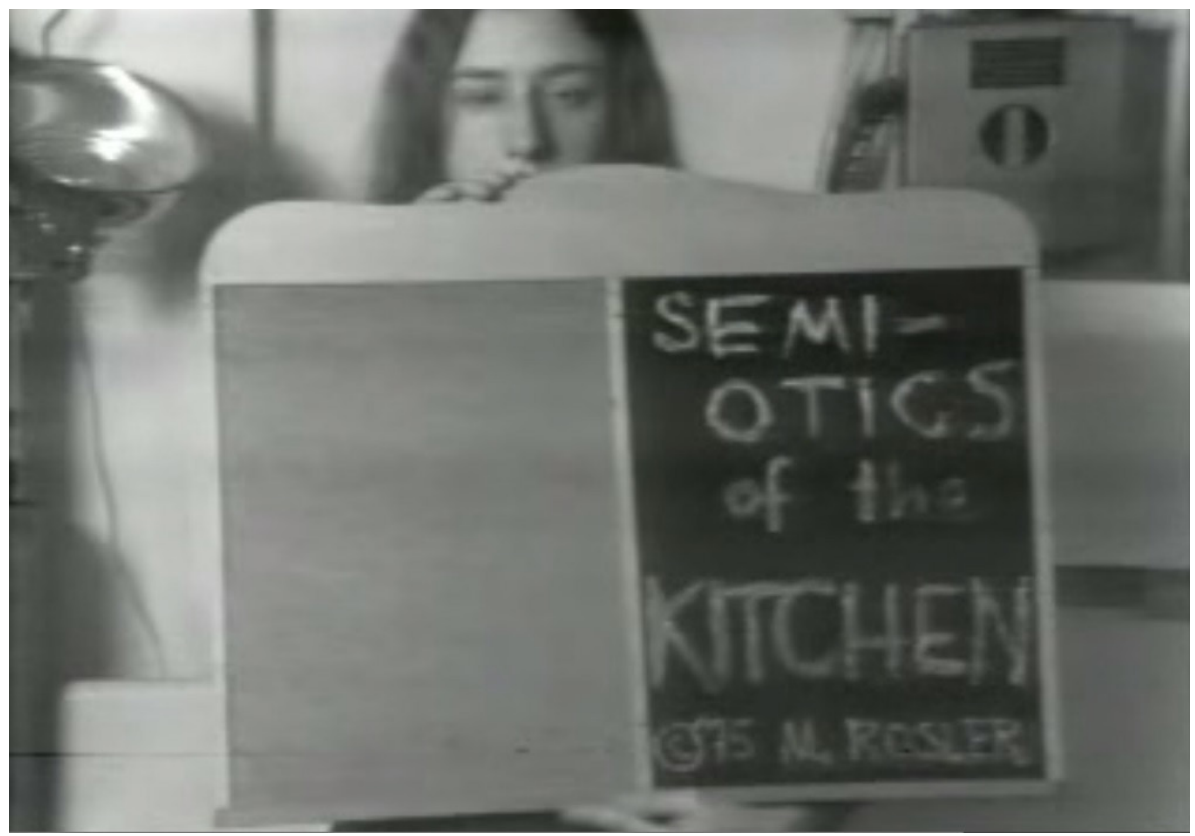

Figura 1. La pizarra como elemento de la pedagogía rosleriana. Semiotics of the kitchen (Martha Rosler, 1975). (C) Martha Rosler

Analicemos esta primera imagen, que será fundamental para entender el resto de los componentes que configuran la obra. Podemos ver como el uso de la pizarra para escribir el título de la videoperformance obedece lógicamente a la falta de recursos técnicos propios del arte underground. Ahora bien, en esta 
imagen resuena otra de un filme de Jean-Luc Godard, La Chinoise (1967), una de las referencias ineludibles para la artista norteamericana, ya que en muchas de sus obras se apropia de algunas de las innovaciones estilistas de este cineasta francés (Cottingham, 1991). De hecho, llegó a conocer a Godard cuando este fue a la Universidad de California a impartir una conferencia sobre el cine de Roberto Rossellini (Rush, 2000).

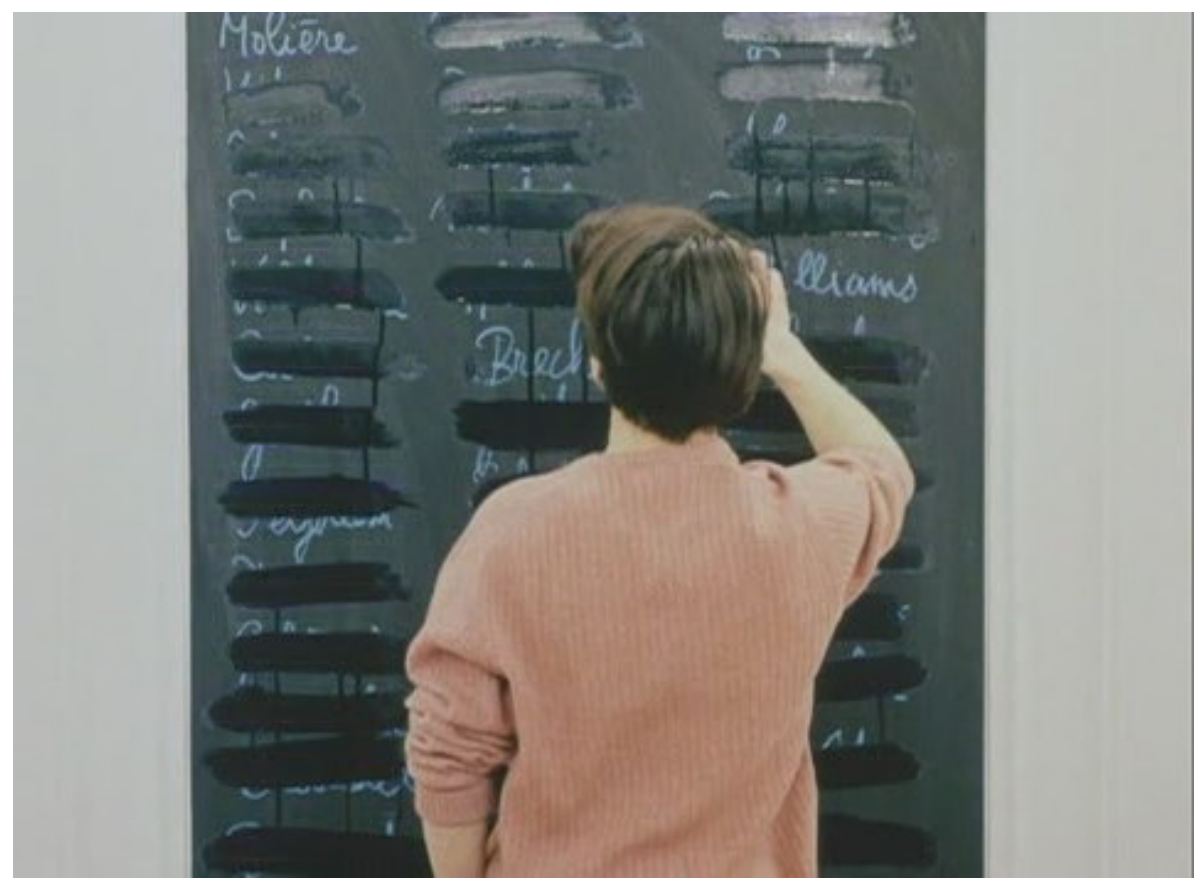

Figura 2. La pizarra como elemento de la pedagogía godardiana. La Chinoise (JeanLuc Godard, 1967), Francia: Anouchka Films / Les Productions de la Guéville / Athos Films / Parc Film / Simar Films.

En la imagen de la pizarra aparecen ordenados en tres columnas los nombres de algunos de los más grandes dramaturgos de la historia mientras el actor Jean-Pierre Leaud interviene sobre la superficie borrando progresivamente cada uno de los nombres menos uno: Brecht. Este plano puede considerarse como la inauguración del Godard pedagogo que defiende un cine donde se 
va a aprender, y en consecuencia, abre el camino del definitivo abandono del cine comercial, que para el cineasta francés es ese cine donde se va a dormir (Daney, 2004). La obra de Godard, sobre todo a partir de mayo del 68, abandona progresivamente el territorio de la ficción para adentrarse por las sendas del documental y el cine-ensayo, géneros más propicios para el proyecto pedagógico godardiano. La pizarra, de modo similar, le sirve a Rosler para pensar y para hacer de la imagen un lugar para enseñar y aprender. Así, la pizarra se convierte en el elemento que nos anticipa: que la cocina de Rosler, va a ser un aula; el título de su vídeo, una asignatura universitaria; y la artista, ocupará el lugar de la maestra.

De otra parte, debemos apuntar que la asunción de esta pedagogía como práctica artística hunde sus raíces en el teatro de Bertolt Brecht, influencia común a Godard y a Rosler. Brecht pretendía fracturar el proceso identificador del teatro clásico basado en el concepto de catarsis que Aristóteles definió en su Poética para que, a través del distanciamiento (Verfremdungseffekt), sea posible el juicio crítico (Benjamin, 1998). Rosler se apropia de esta teoría del distanciamiento que permite que la obra no termine en su exposición, en la medida en que activa el pensamiento crítico en el espectador y lo convoca a adoptar una posición respecto a la problemática plateada. Alexander Alberro corrobora esta tesis al escribir que para Rosler "era imperativo que el arte tratara sobre cuestiones actuales, ya que su principal misión era educar al público a partir del distanciamiento brechtiano para impedir la catarsis, la identificación del espectador.” (1999, p. 72).

\section{La Semiótica como Práctica Disruptiva de las Normas Sociales}

Analicemos ahora el contenido, el texto escrito en la pizarra. ¿Qué ocurre con la palabra "Semiotics"? ¿Por qué aparece rota, partida en dos mitades: semi-otics? ¿Por qué hay una quiebra en el significante? ¿Qué consecuencias podemos extraer de dicha ruptura?

En primer lugar deberíamos apuntar que, desde el punto de vista etimológico, fue John Locke el primero en hablar de semiótica, palabra procedente del griego semeion, que significa "signo", conjugado con el sufijo -tikos que se traduce como "relativo a" (Locke, 1999). Es decir, la semiótica es la disciplina que estudia los signos en la vida social y que gracias a los pioneros trabajos de Ferdinand de Saussure (1986), que definía a esta ciencia con el nombre de semiología, y de Charles Sanders Peirce (1982-2000), con su clasificación 
de los signos, va a alcanzar una trayectoria exitosa a lo largo del siglo XX. La palabra tomada del griego, en masculino, semioticos, definía la disciplina que estudiaba los síntomas de las enfermedades. Siguiendo la senda de la etimología cabe preguntarse: ¿Qué signos de la vida social va a presentar Rosler en su obra? ¿Son esos signos algún tipo de síntoma de una enfermedad de la realidad social?

En segundo lugar, hay que hacer alusión al modo en que la quiebra del significante conforma el elemento prefijal "semi-", que significa "medio o mitad". ¿A qué mitad se refiere la artista? Desde las coordenadas del estructuralismo, íntimamente emparentado con la semiótica, se entiende que en una estructura se disponen elementos diferenciales que funcionan como signos y que, siendo diferentes, son interdependientes (Auzias, 1992). Los signos de la vida social que va a mostrar Rosler tienen que ver con el papel de la mujer dentro de las coordenadas impuestas por la familia patriarcal. ¿Por qué ha estado durante siglos encerrada en el espacio doméstico? ¿Cuáles son las causas histórico-sociales de esa reclusión? Lo que va a mostrar la semiótica de Rosler es que el disciplinamiento de la mujer se debe a una enfermedad social: la familia patriarcal. Y lo va a hacer por medio de una performance que escenifica los síntomas de la alienación de la mujer. Por eso no es gratuito que la palabra semio (signo) esté rota y configure otra palabra, semi (la mitad), que Rosler quiere defender, reivindicar y resignificar. Además, se encarga de separar esa mitad (semi-) del elemento masculinizador simbolizado por la letra "o". De este modo, se trata de mostrar el sentido de la mitad, el signo de la mujer. La mujer ha sido significada por los intereses masculinos, por las estructuras de una sociedad patriarcal que la relega a un papel secundario en la estructura familiar occidental y la convierte en poco menos que una esclava del hogar, y esto lo va a mostrar Rosler con una serie de coreografías a medio camino entre la violencia, el absurdo y la comedia.

Tras el título de la videoperformance, comienza Rosler su acción. Vemos que aparece en una cocina utilizando una serie de objetos (cuchillos, platos, sartenes, etc.) de manera violenta y automatizada, con una expresión facial deshumanizada y vacía; a la vez que va pronunciando el nombre de cada uno de los objetos utilizados siguiendo un orden alfabético: Apron (A), Bowl (B), Chopper (C) y así hasta la letra Z. En esta acción utiliza una serie de elementos escenográficos, kinésicos y prosódicos que conforman un dispositivo productivo tan contestatario como paródico. Veamos estos elementos. Los elementos escenográficos son dos: el lugar de la acción, esto es, la cocina, y los utensilios propios de las actividades domésticas: cuchillos, batidora, 
etc. Los elementos kinésicos también son dos: el gesto violento, exagerado y automatizado; y el rostro impasible y deshumanizado. Y por último el elemento prosódico: la pronunciación mecanizada del nombre cada uno de los utensilios siguiendo un orden estrictamente alfabético.

Rosler, en su práctica semiótica sobre el espacio doméstico, muestra la cocina como un signo de opresión masculina y las coreografías como un signo de las maquinaciones de control sobre los cuerpos:

Es el signo de una cocina. La acción es el signo de una opresión. Y Semiotics of the Kitchen, que realicé cuando regresé a Nueva York en 1974-1975, es sobre «representaciones televisivas de». Para Semiotics tuve que utilizar la cocina del loft de alguien que conocía porque se suponía que no debía parecer una cocina de casa suburbana. Tenía que parecer una especie de extraño escenario, como el signo de una cocina. (2006, p. 104)

Ahora bien, el automatismo agresivo y deshumanizado aparece como una pose irónica que tiene la firme intencionalidad de mostrar un cuerpo que ya no quiere ser dócil, que pretende desligarse de la trama de la dualidad sexuada que ha impuesto la mirada patriarcal a través del lenguaje y la estructura familiar. Por otro lado, la enumeración alfabética de los objetos funciona como un sarcasmo hiriente que muestra los agenciamientos de poder del lenguaje, esto es, la forma en que el lenguaje da órdenes y codifica la realidad social. Ese orden del lenguaje, que localiza los cuerpos según entidades fijas y determinadas y que, por tanto, tiene una funcionalidad disciplinaria, de vigilancia de sobre las posibilidades en el campo sociopolítico, es desterritorializado por la acción de la artista que revierte dicho orden simbólico. Cuando Judith Butler (2002), en el ámbito de la teoría feminista, critica el psicoanálisis freudiano haciendo alusión a la función simbólica, en tanto que representación de un espacio sociopolítico donde los sujetos se insertan en posiciones fijas y donde el varón ocupa el lugar de la ley en la familia, resulta claro que a lo que está apuntando es a que hay que reivindicar una función semiótica, pues ésta a diferencia de la función simbólica, tiene una función disruptiva y crítica con las normas sociales impuestas por el poder establecido. En este sentido, la crítica de Butler al psicoanálisis radica en que este ha impuesto el triángulo edípico familiar como única forma social posible y, por tanto, "transforma un modelo de familia patriarcal históricamente condicionado en un rasgo de la condición humana universal.” (2002, p. 284). De ahí la rebelión semiótica 
de Martha Rosler contra la estructura familiar. Esta tiene como función, entre otras, disciplinar los cuerpos, asignarles un lugar, cuestión estudiada por Michel Foucault (2000) en Vigilar y castigar, en el capítulo "los cuerpos dóciles", donde teoriza sobre los diversos modos de regulación y control sobre los cuerpos. Esta tesis es reformulada por Butler en clave feminista: el cuerpo de la mujer en la familia occidental está localizado y codificado para tareas de producción -tareas del hogar- y de reproducción sexual. Por ello, el campo del lenguaje es el que posibilita la distribución ordenada de los cuerpos en identidades fijas con fines de disciplinamiento social: la poética dominante deviene ontología y política.

De este modo, podemos identificar tres campos de batalla donde se ejerce el control social de las mujeres y donde es común que la crítica feminista intervenga por medio de prácticas disruptivas que descentren y desvíen dichos encuadramientos: el lenguaje, la ontología y la política.

\section{La Disrupción del Lenguaje}

Rosler elabora su performance introduciendo un personaje casi cómico, una especie de Buster Keaton inexpresivo e hierático dentro de una circunstancia hostil y dramática como es la alienación femenina en las familias capitalistas occidentales. Silvia Eiblmayr llega a definir sus prácticas artísticas como "una comedia de los Hermanos Marx desde una postura feminista" (1999, p. 155). Esta alienación, este extrañamiento, es producido por la acción de la familia, que impone un conjunto de ideas pretendidamente verdaderas y universales que son sólo producto de una trama cultural elaborada por el poder masculino. El orden diacrónico del alfabeto funciona en la performance de Rosler como un elemento que control social, como una ley incuestionable que hay que deletrear de manera automática. Así, la articulación de las letras del alfabeto, su encademamiento, sirve para componer el significado del sujeto. Según Lacan es a través del encademamiento de los significantes como surge el sujeto, lo que él llama el sujeto barrado, esto es, el sujeto atravesado por lo Otro del lenguaje: "El sujeto es la resultante, el resto de la operación que afecta al cuerpo una vez que este es atravesado por el lenguaje." (Albano, 2002, p. 164). Estos significantes del personaje de Rosler son los de un orden simbólico dominado por la autoridad del Nombre del Padre, representante de la ley el núcleo familiar, y que en el ámbito de lo social relacionamos con la autoridad totalitaria del Estado y del Capital. Así, la performance de 
Rosler muestra como la familia está inscrita e instituida por el Estado y, por ello, podemos leer esta obra artística desde la perspectiva butleriana de la crítica a la familia. La aproximación al pensamiento de Judith Butler de María Femenías arroja luz sobre este modo de institución:

La familia depende del poder del Estado que la instituye y la legitima (...) No puede haber familia sin Estado; sin una concepción política que establezca normas culturales y construya una inteligibilidad cultural en la que la familia se inscribe (...) Las dos cuestiones que le interesa plantear a Butler son si puede haber parentesco sin el soporte y la mediación del Estado, y si puede haber Estado sin el soporte y la mediación de la familia. ¿Pueden ambos sostenerse independientemente? (2003)

De algún modo, el cuerpo de la mujer, en el núcleo familiar, es convertido en una especie de máquina portadora de unos signos. El cuerpo como lugar donde se ejerce el poder por medio del lenguaje. De este modo, el cuerpo de la mujer es un cuerpo moldeable, amorfo, plástico, un cuerpo utilizado, dominado y coaccionado mediante la aplicación de una serie de automatismos, mediante la imposición de unos hábitos sumamente artificiales. La manipulación y la conformación del cuerpo de la mujer se va ejerciendo en todos los niveles de lo social. Comienza en la escuela, donde los juguetes de las niñas (muñecas, cocinas, cacharritos de todo tipo) sirven para aleccionarla y educarla como madre, y termina en la familia, espacio social donde escenificar las lecciones aprendidas. En este sentido, podemos decir para la mujer lo que Michel Foucault afirma para los soldados del siglo XVIII: "es dócil un cuerpo que puede ser sometido, que puede ser utilizado, que puede ser transformado y perfeccionado." (2000, p. 140).

Y todo comienza en la escuela, que es el espacio donde el lenguaje impone su dominio. Rosler es consciente de ello y de ahí su propuesta de una pedagogía emancipadora, de una contraescuela en la medida en que en la escuela normalizadora hay que aprender las bases duales de la gramática: masculinofemenino, singular-plural, sujeto-verbo. Ahora bien, hay que señalar que entre estas dualidades gramaticales se dan correlaciones que determinan los modos del hombre: sujeto singular, portador de derechos y de propiedades; y los modos de la mujer: una pluralidad en tanto que la maternidad es la posibilidad de un ser de engendrar otro ser -y por tanto vive una vida proyectada a los demás, en los otros- pero la mujer también es verbo, acción, práctica. Su 
ser implica un hacer. Y en ese hacer debe estar la rebelión, la contestación. Un hacer, un acto performativo que sirva para desbloquear las argucias del lenguaje dominante.

La performance de Rosler muestra el mandato de la sociedad patriarcal, esto es, el lenguaje como forma de poder sobre los cuerpos: los disciplina y los somete a un estado de esclavitud velada en la medida en que nos muestra una apariencia de bienestar, una "jaula de Oro" ocultada por los dispositivos patriarcales. Publicidad, televisión, radio y la prensa construían una imagen idílica del hogar que empañaba la explotación laboral de la mujer. En este sentido, el disciplinamiento lo ejercen las determinaciones culturales de la sociedad y sus dispositivos de ideologización, que, sin duda, son los que aplica el patriarcado a través del lenguaje. Las constricciones culturales e institucionales hacen de la mujer un sujeto sumiso cuya única aspiración es el matrimonio, la reproducción y la educación de los hijos, aparcando a un lado sus aspiraciones vitales y profesionales. Es lo que Betty Friedan (1970) ha llamado la mística de la feminidad. En concreto, el matrimonio es el enlace sagrado que conforma la familia y que para el feminismo es una forma de opresión legal: "el matrimonio proporciona estatus legal a la forma de la familia." (Butler, 2010, p. 145). En este sentido, la crítica feminista a la familia es correlativa a una crítica al Estado como institución normalizadora de la sexualidad.

Cuando Rosler pone en marcha la enunciación de la serie alfabética de los objetos de cocina está escenificando las estrategias del poder del lenguaje sobre el cuerpo, está asumiendo el problema de la construcción lingüística de la mujer en las familias occidentales. Esta puesta en escena determina el modo en que los actos performativos que realiza la mujer en su cotidianidad están construidos por las normas, por las consignas del orden social hegemónico que sirven para oprimir y sujetar a los cuerpos mediante la inscripción en ellos de la ley bivalente que diferencia al hombre de la mujer. Este lenguaje que Jaques Derrida (1989) define como falogocéntrico: conexión entre la palabra y el falo en tanto que significante simbólico del poder masculino. Así, el Estado falogocéntrico es el que determina, según la crítica feminista, como han de ser las relaciones sociales normalizadas en la familia.

Ahora bien, en la performance de Rosler, a pesar del automatismo de la pronunciación y del sometimiento al orden simbólico del lenguaje, observamos dos elementos realizativos que adoptan una posición crítica respecto a las coerciones dominantes. En primer lugar, sus actos son violentos 
y agresivos, lo que nos lleva a pensar que el personaje interpretado por Rosler trata de escapar del dominio normalizador de la Familia-Estado. En segundo lugar, el uso que hace de los objetos no tiene nada que ver con su uso común: cada objeto es descontextualizado de su función específica y utilizado de manera desviada, no regularizada, casi metafórica y poéticamente.

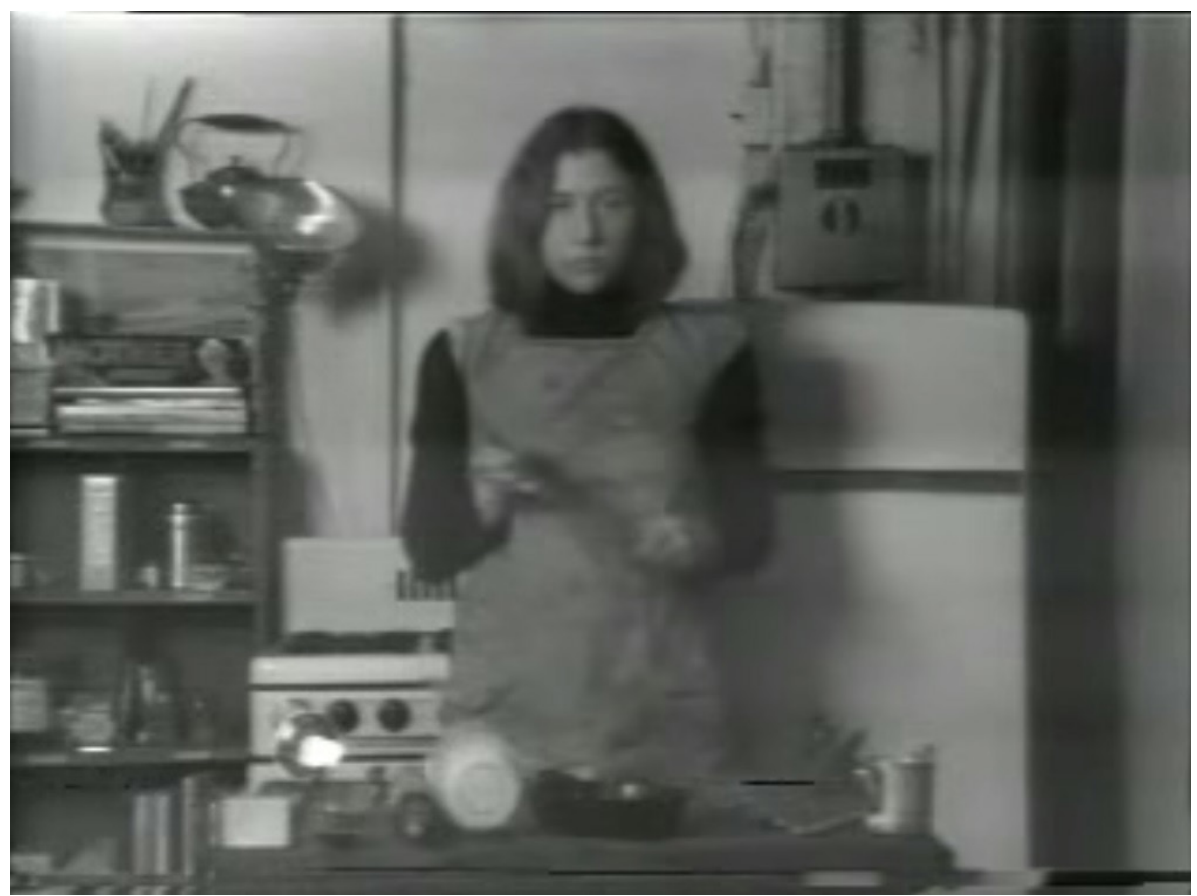

Figura 3. Uso no regularizado de los utensilios de cocina. Semiotics of the kitchen (Martha Rosler, 1975). C Martha Rosler

Primero marca con el gesto su funcional normalizada, su sentido propio: cuando agarra el cuenco simula que está batiendo la comida pero, a continuación, coge una plancha y golpea con violencia sobre su superficie. Luego continúa con otros usos desviados: utiliza un tenedor sobre un rayador, clava un pica-hielos en la sartén o usa el exprimidor sobre su propia mano. Así el dispositivo que ejecuta Rosler con su acción se construye de dos elementos 
significativos: el elemento en sentido propio, es decir, la función normalizada de su uso, y el elemento en sentido figurado: su función desviada o poética. La desviación del uso normal de los utensilios de cocina es el elemento crítico que rompe la función que le ha sido asignada y, por tanto, es la rebelión innovadora y metafórica que produce una ruptura, un acontecimiento que se posiciona contra la norma. El acto performativo de Rosler rompe con el lugar determinado de las palabras, rasga las significaciones propias de la tareas del hogar y cuestiona la normalidad dominante encarnado un uso anómalo y poético de las significaciones. Si como afirman Deleuze y Guattari "la pragmática es la política de la lengua" $(1999$, p. 87), entonces para luchar contra las ideas transmitidas por la familia como consignas, lo que hay que hacer es introducir el delirio poético, que es aquello ajeno a la ley. Y esto es lo que hace Rosler: hacer delirar el uso normalizado y el significado propio de los objetos de cocina de manera que su práctica ejemplifica un trabajo biopolítico plasmado en el interior del lenguaje. Se trata de romper el lenguaje dominante desde dentro, trabajándolo, luchando contra él, transformando su orden lógico de cara a transformar también la sociedad.

La práctica de la performance como descentralización, como práctica a contracorriente, metafórica y descontextualizadora bebe de las fuentes de un trabajo previo de Rosler centrado en la fotografía. En su obra Bringing the War Home (1967-1972), contemplamos ya ese trabajo de la sutura de la diferencia y de la coexistencia de elementos descontextualizados por medio de la técnica del collage, con fines de crítica política. 


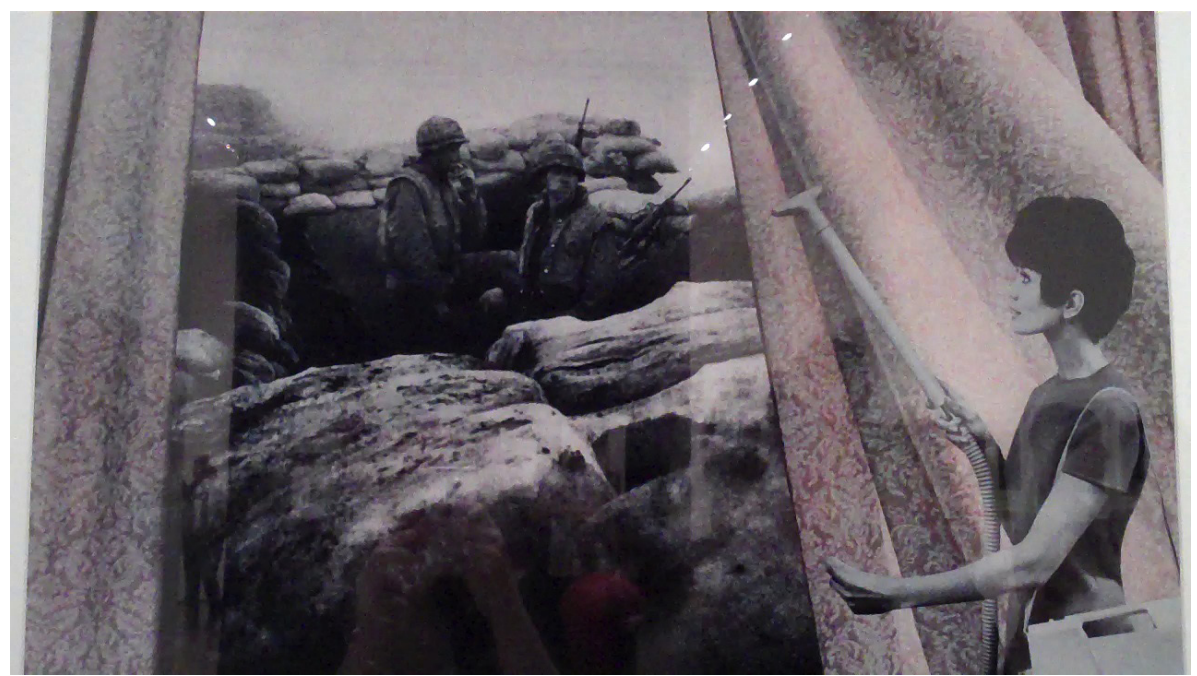

Figura 4. Coexistencia de elementos descontextualizados por medio de la técnica del collage con fines de crítica política. Cleaning the Drapes from the series House Beautiful: Bringing the War Home 1967-72. C Martha Rosler

En esta imagen, Rosler crea un efecto en el que se evidencian las suturas entre las fotos de guerra y de lo cotidiano. De alguna manera muestra como la guerra también está en casa, como el núcleo familiar deviene campo donde se ejerce una violencia simbólica, es decir, como el espacio doméstico, íntimo y personal también es, como dice Kate Millett (1971), el lugar de lo político. La recontextualizacion de imágenes naturalistas de la guerra y el hogar familiar permitía obtener nuevas perspectivas de lo habitual y lo cotidiano. El empleo de objetos cotidianos para generar nuevas relaciones servía a la artista para practicar la crítica política del hogar y de la familia.

\section{La disrupción de la identidad}

Al final de la performance, Rosler se convierte en letra, en un utensilio más ya que con su propio cuerpo dibuja las últimas letras del alfabeto: $\mathrm{U}, \mathrm{V}, \mathrm{W}$, $\mathrm{X}, \mathrm{Y}$ y Z. Su cuerpo parece estar regulado por el orden de las letras, parece 
segmentarizado por el disciplinamiento que hace útil su cuerpo en el seno de la sociedad familiar y que reduce sus fuerzas reivindicativas y su poder de desobediencia. Pero prestemos atención a las tres últimas letras del alfabeto:
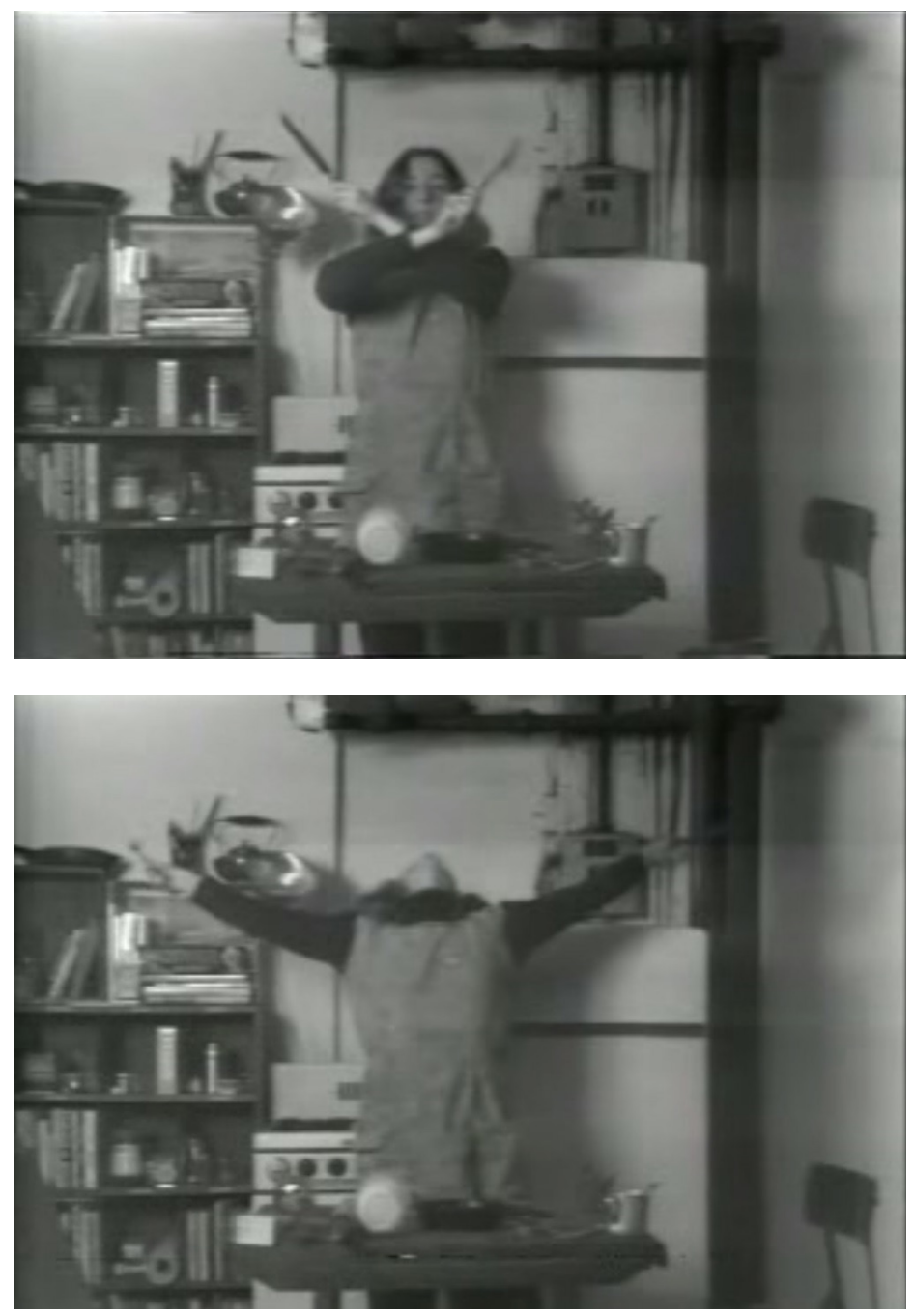

Figuras 5 y 6. El cuerpo regulado por la letra. Semiotics of the kitchen (Martha Rosler, 1975) (C) Martha Rosler 
En estas letras vemos encarnada la actitud de Rosler respecto a la sociedad patriarcal que mediante la estructura familiar ha coaccionado a la mujer $y$ la ha convertido en una esclava del hogar. La letras X y Y sabemos que son la expresión genética del macho. Está escrito en la acción con claridad: la letra Y, diferencia sexual cronosómica de los machos, es simbolizada con un gesto corporal semejante al de Jesuscristo en la cruz, mientras que la letra $Z$ la dibuja con el cuchillo en el aire simulando el gesto del Zorro. O lo que es lo mismo: el hombre dominante, la letra $\mathrm{Y}$, ha de ser sacrificado en pro de la igualdad social y la justicia que reivindica con la marca del Zorro en su lucha contra los tiranos.

Este gesto nos abre el escenario para tratar el problema de la identidad dentro de la crítica feminista prestando especial atención al concepto de género, cuya funcionalidad es la de vislumbrar como las diferencias sexuales entre hombres y mujeres no son otra cosa que construcciones sociales que tiene implicaciones traumáticas. Y es la institución familiar la que se encargar de inscribir esas diferencias pues "ese trauma sexualizado se origina en la familia." (Butler, 2002, p. 286). Así, las luchas del feminismo radican en mostrar la diferencia sexo/género. En su crítica a Simone de Beauvoir, la propia Judith Butler lo expone en los siguientes términos:

"Una no nace mujer, se hace" -la formulación de Simone de Beauvoir distingue sexo de género y sugiere que el género es un aspecto de la identidad que se adquiere gradualmente [...] el sexo debe entenderse como una invariable, anatómicamente distintiva, de los aspectos fácticos del cuerpo de una mujer mientras que el género remite a la forma y el significado cultural que adquiere el cuerpo, lo modos variables de la aculturación del cuerpo. (1998, p. 10).

Ahora bien, Butler entiende que el cuerpo femenino es ya una construcción de significados culturales que, por mediación de la institución familiar, se convierte en objeto de un proceso identitario. Siguiendo a Derrida, considera que esta construcción es la del poder masculino y falocéntrico, que hace uso de todos los recursos de la ideología -escuelas, poder legislativo, medios de comunicación, teorías científicas y filosóficas- para reproducir los códigos dominantes. De este modo, la ideología masculina es una suerte de institución legisladora que se inscribe en el cuerpo de las mujeres y que determinan cuales deben de ser los comportamientos normalizados, pero también un ojo todopoderoso que vigila que estos comportamientos se cumplan. La 
mujer tiene un estilo corporal, una pose, una sensibilidad, una identidad que ha sido configurada biopolíticamente. En este sentido, el género no es algo políticamente neutro sino algo que está significado desde un origen pretendidamente natural. Es decir, el Estado a través de la institución familiar legisla como han de ser las mujeres. Y esto es justo lo que muestra Rosler en Semiotics of the kitchen: como el género ha sido construido por el poder del lenguaje sobre el cuerpo y por la asignación de una identidad fija y definida.

¿Qué puede hacer la mujer ante este sistema de cálculos y predeterminaciones familiares que la someten? La respuesta que da Butler (2002) es que la mujer se hace en sus actos performativos. Algo que Rosler encarna en su práctica corporal de contrapoder a través del acto performativo de ruptura del orden lineal del significante semio (signo) para enunciar el significante semi (la mitad, la mujer), de los actos performativos desviados de la norma en el uso anómalo de los utensilios de cocina y de los actos performativos de guerra contra el poder despótico del significante XY. Estas prácticas disruptivas dan cuenta de cómo la identidad sexual es una ficción configurada por los discursos y las prácticas de poder patriarcal. La identidad es acción y no una esencia fija como pretende el ideal normativo. Por eso son necesarias las rupturas y las incoherencias de las continuidades que distribuye la cultura occidental masculina. Se trata de romper el lenguaje para romper la identidad como programa de acción política para, así, encontrar nuevos modos de comunidad en los márgenes de la familia occidental. Así lo ve nuevamente Judith Butler:

Creo que tenemos que distinguir "familia" de "parentesco", pensando parentesco como ese grupo de personas de las que dependemos y que dependen de nosotros, una comunidad que participa de las mayores celebraciones y pérdidas de nuestras vidas. Creo que es un error restringir la idea de parentesco a la familia nuclear. Creo que todos necesitamos producir y sostener este tipo de comunidades. Demasiado peso emocional se deposita sobre la familia y la pareja, y encima estas instituciones deben abrirse a mundos más amplios. No es necesario estar unidos por la sangre o por el matrimonio para convertirse en esenciales unos para los otros. No solamente tenemos que imaginarnos más allá de estas maneras de relacionarnos sino también cómo podríamos vivir en ellas (2009).

Por tanto, los actos performativos de Rosler son actos corporales que se desvían de la norma familiar para producir una resignificación. Actos que emparentados con el sentido que da Butler a la parodia y que recuerdan a 
"la «risa desbordante» de Pierre Rivière, cuyo acto de asesinar a su familia o quizá, para Foucault, a la familia, parece negar bastante literalmente las categorías de parentesco y, por extensión, de sexo.” (2007, p. 221). Son modos de lucha contra las normas de identidad que impone la sociedad a través de la familia y que localizan a la mujer bajo la autoridad masculina. La deshumanización del personaje de Rosler muestra el efecto de la alienación, pero sus gestos y expresiones violentas sirven para rasgar el cuerpo culturalmente construido: son sin duda una marca de resistencia. El acto performativo es un desplazamiento paródico contra el poder que "da lugar a la fluidez de las identidades que sugieren la apertura de la resignificación y la recontextualización; la proliferación paródica priva a la cultura hegemónica de la naturalización o de la esencialización de las identidades.” (Butler, 2007, p.138).

\section{La Disrupción de la Política}

La disrupción del lenguaje y la disrupción de la identidad que propone Rosler en Semiotics of the kitchen van ligadas a la disrupción política que propone el feminismo en su crítica a la familia patriarcal. El feminismo, como novedad teórica crítica, asume su responsabilidad de contrapoder. Toda nueva proposición teórica nace en un contexto social, en una matriz cultural que, o bien se pretende justificar y reproducir mediante sus argumentos y conclusiones, o bien se la descentra con la idea de iluminar zonas no transitadas. El primer modelo de creación teórica tiene un carácter ideológico, en la medida en que reproduce el orden social dominante, es decir, en tanto en cuanto demarca las reglas de juego de dicho orden social, mientras que el segundo modelo se adhiere a la pasión por la crítica a lo establecido como verdadero, natural, lógico o común y propone nuevas alternativas.

En este orden de cosas la teoría feminista esquiva la ideología para establecer un discurso crítico con las formas de poder haciendo hincapié en los modos de dominación masculina o lo que es lo mismo: los modos de ser del patriarcado. Este cuestionamiento supone una transformación de lo que a lo largo de la historia han ido configurando los dispositivos de ideologización, donde la mujer tenía su lugar natural y su esencia intrínseca.

El feminismo de la primera ola tiene en el punto de mira a la familia tradicional a la que considera el mayor enemigo en el proceso emancipatorio de la mujer. $\mathrm{Su}$ trabajo deconstructor del orden patriarcal se centra en la desmitificación de la familia y de la maternidad en tanto que yugos opresores. La familia y la 
maternidad eran objeto de crítica por parte de autoras como Kate Millett, Betty Friedan o Shulamith Firestone en la medida en que configuraban estructuras que reproducían las formas del poder político y económico, esto es, eran el resultado de las prácticas reguladoras y normalizadoras del binomio EstadoCapital. De este modo, la familia deja de ser ese lugar de seguridad y confort, ese Paraíso publicitado en la sociedad americana de los años 50 y se convierte en el escenario del horror, el campo de batalla, el espacio del control de los cuerpos y las mentes de las mujeres. En definitiva, no es más que el resultado de una estrategia alienante contra la que las mujeres adoptarán una posición insurgente.

Veamos las ideas principales de la crítica a la familia desde las coordenadas de la teoría feminista:

En primer lugar, la crítica feminista describe el hogar como el espacio familiar donde se ejerce el disciplinamiento y la opresión de la mujer. ¿Cómo se ejerce este disciplinamiento? ¿Qué finalidad tiene? Hay que señalar que este disciplinamiento es una forma de esclavitud velada en la medida en que nos muestra una apariencia de bienestar, una jaula de Oro ocultada por los dispositivos patriarcales. La publicidad, la televisión, la radio y la prensa configuraban una imagen de ensueño del hogar que empañaba la explotación laboral de la mujer. En este sentido, el disciplinamiento lo ejercen las determinaciones culturales de la sociedad y sus dispositivos de ideologización, que sin duda son los del patriarcado, y que sirven para ocultar la sistemática opresión. Se establece así una diferenciación respecto a los espacios que habitan hombres y mujeres. La mujer termina por estar relegada al espacio doméstico y el hombre al espacio público. Y esta división topológica tiene sus consecuencias: el hombre provee a la familia de dinero para el alimento y la mujer, en posición de inferioridad, se siente en deuda.

En segundo lugar, lo que Friedan (1970) denomina la mística de la feminidad convierte a la mujer en un ser-en-su-casa cuya única funcionalidad es la de la reproducción y la de la educación de los hijos. Este ejercicio de anulación de los sueños y las aspiraciones propios hace que la mujer se suma en una profunda apatía, soledad y frustración, haciendo de ella una esclava laboral. La base material del patriarcado es el control del hombre de la fuerza laboral de la mujer. Un control que la excluye de los procesos productivos.

Y en tercer lugar, la afirmación de la abolición de la familia que heredan del pensamiento marxista. Friedrich Engels (1992) en El origen de la familia, de la propiedad privada y del Estado afirmaba la profunda desigualdad que se daba en las familias burguesas que reducía el papel de la mujer a la procreación 
de los herederos del marido a cambio de comida y casa, lo que hacía de esta turbia relación poco menos que una práctica de prostitución. Max Horkheimer (2003), en Autoridad y familia, releía el marxismo para conformar su Teoría Crítica y consideraba que en la familia siguen vivos los dispositivos del sistema feudal. Estas ideas son recogidas por las feministas marxistas que ven que la familia no sólo es el mayor obstáculo para su liberación social sino que también es el reflejo de la sociedad capitalista dominante.

Estas ideas que la teoría feminista ha esgrimido contra el orden familiar las podemos ver inscritas en la praxis artística de Rosler. En su obra, el descentramiento de la ideas dominantes que el lenguaje del poder masculino ha impuesto mediante la ideología va acompañado de una crítica a la identidad cultural y a la política en la medida en que sus acciones performativas muestran los modos de internalización de los medios de control social que se ejercen en el hogar familiar. Por ello, Rosler hace de lo doméstico un espacio no desconectado de la política ya que es el resultado y el efecto de esta.

En suma, para Rosler la cocina es el signo del poder masculino donde la mujer padece una serie de obligaciones domésticas que impiden su emancipación y, en consecuencia, es un espacio marcado por la política donde se distribuyen los roles entre hombres y mujeres y toda una jerarquización opresora. Por tanto, su videoperformance no tiene tan sólo una carácter feminista sino que también esconde una posición marxista heredada de sus referencias artísticas (Godard, Brecht) y filosóficas (Adorno, Jameson), las cuales, le sirven para investigar y describir los problemas cotidianos de la mujer desde una óptica irónica y cuya problemática principal es la de mostrar como lo macropolítico está íntimamente ligado con lo micropolítico, con el espacio del hogar familiar.

\section{Conclusiones}

Deletrear un texto audiovisual como Semiotics of the kitchen desde las coordenadas del pensamiento postestructuralista y feminista nos ha servido para dar cuenta de la configuración del cuerpo social dominante y de la inscripción del cuerpo de la mujer en el mismo a través de su rol familiar. La performance de Rosler plantea de forma poética y humorística los modos de subversión de la familia patriarcal a través de tres ejes fundamentales que están conjugados y que constituyen una organicidad. El eje del lenguaje tiene la función de producir los discursos y las ideas que se transmiten en todas las instancias sociales, y en particular en la familia, y que permiten la 
creación de identidades fijas y localizadas. Estas identidades no son más que simulacros o ficciones cuya funcionalidad remite al ideal de estabilidad que imprime la familia patriarcal mediante el control psíquico y físico con fines de disciplinamiento político.

Por tanto, el estudio de esta performance de los años 70 nos ha servido para establecer dos funciones en el estudio de la institución familiar occidental. Una función crítica que muestra que las formas poéticas dominantes -estructuras del lenguaje, narrativas literarias o cinematográficas, relatos publicitarios- están adheridas a una ontología -que distribuye a los seres y a las cosas según un orden pretendidamente natural-y a una política -el Estado-Capital como forma de control. Y una función creativa que abre una senda de nuevas posibilidades poéticas, ontológicas y políticas que son las que estamos viviendoenla actualidad y que tienen una filiación subterránea con estas prácticas artísticas, militantes, filosóficas y políticas del feminismo que alcanzaron su punto de ebullición en los 70. Y estas nuevas formas, sin duda, van a instituir nuevas comunidades, nuevos modos de relación más allá de la estructura familiar tradicional.

\section{Referencias}

Albano, S. (2002). Glosario de términos lacanianos. Buenos Aires: Quadrata.

Alberro, A. (1999). "La dialéctica de la vida cotidiana: Martha Rosler y la estrategia del señuelo". En ROSLER, Martha, Posiciones en el mundo real.

Barcelona: Museo d'Art Contemporani de Barcelona.

Armstrong, C. y De Zegher, C. (eds.) (2006). Women Artists at the Millennium. Cambridge, MA: MIT Press.

Auzias, J.-M. (1992). El estructuralismo. Madrid: Alianza.

Baigorri, L. (2004). Vídeo. Primera etapa: El vídeo en el contexto social y artístico de los años 60/70. Madrid: Brumaria.

Barthes, R. (2001). S/Z. Madrid: Siglo XXI.

Belloir, D. (1981). Vidéo art explorations. París: Cahiers du Cinéma.

Benjamin, W. (1998). Tentativas sobre Brecht, Iluminaciones III. Madrid:

Taurus.

Butler, J. (1998). "Sexo y género en $E l$ segundo sexo de Simone de

Beauvoir", Mora, 4. 
Butler, J. (2002). Cuerpos que importan. Buenos Aires: Paidós.

Butler, J. (2007). El género en disputa.Madrid: Paidós.

Butler, J. (2010). Deshacer el género. Madrid: Paidós.

Butler, J. "Entrevista a J. Butler". En <http://www.pagina12.com.ar/diario/ suplementos/soy/1- 742-2009-05-09.html>, consultado el 02-01-2014.

Cottingham, L. (1991). “The War is Always Home: Martha Rosler". En

$<$ http://www.martharosler.net/reviews/cottingham.html $>$, consultado el 02-01-2014.

Daney, S. (2004). Cine, arte del presente. Buenos Aires: Santiago Arcos editor.

Deleuze, G. y Guattari, F. (1999). Mil mesetas. Valencia: Pretextos.

Derrida, J. (1989). "Entrevista de Cristina Peretti con Jacques Derrida". Política y Sociedad, 3. En http://revistas.ucm.es/index.php/POSO/ article/view/POSO8989230101A/30666

Eiblmayr, S. (1999). “Los personajes de M. Rosler”. En ROSLER, Martha, Posiciones en el mundo real. Barcelona: Museo d'Art Contemporani de Barcelona.

Engels, F. (1992). El origen de la familia, de la propiedad privada y del Estado. Barcelona: Planeta.

Femenías, M. L. (2003). “Aproximación al pensamiento de Judith Butler”.

Conferencia impartida por Doña $\mathrm{M}^{\mathrm{a}}$ Luisa Femenías. Gijón, 5 de diciembre de 2003. En <www.comadresfeministas.com>

Foucault, M. (2000). Vigilar y castigar. Barcelona: Siglo XXI.

Friedan, B. (1970). La mística de la feminidad. Barcelona: Grijalbo.

Horkheimer, M. (2003). Teoría crítica. Buenos Aires: Amorrortu.

Locke, J. (1999). Ensayo sobre el entendimiento humano. México: Fondo de Cultura económica.

Millett, K. (1971). La politique du male. París: Stock.

Peirce, C. S. (1982-2000). Writings of Charles S. Peirce: A Chronological Edition. Bloomington: Indiana University Press.

Rosler, M. (2006). "Video: dejando atrás el momento utópico". En AA.VV., Primera generación. Arte e imagen en movimiento (1963-1986).

Madrid: Museo Nacional Centro de Arte Reina Sofía.

Rush, M. (2000). “ART/ARCHITECTURE; A Pure Artist Is Embraced by the Art World", New York Times, July 9, 2000.

Saussure, F. (1986). Curso de lingüística general. Buenos Aires: Losada. Witting, M. (2006). "No se nace mujer". En El pensamiento heterosexual y otros ensayos. Madrid: Egales. 
Miguel Alfonso Bouhaben: Docente Investigador en la Escuela Superior Politécnica del Litoral, ESPOL, Escuela de Diseño y Comunicación Visual, EDCOM.

Contact Address: Escuela Superior Politécnica del Litoral (ESPOL), Escuela de Diseño y Comunicación Visual, EDCOM. Campus Gustavo Galindo Km 30.5 Vía Perimetral, P.O. Box 09-01-5863, Guayaquil (Ecuador).

E-mail address: mabouhaben@gmail.com 